\title{
A Study of the Representation and Display of History in Japanese Period Architectural Heritage in Taiwan
}

\author{
Tsai-Chuan Chang
}

\begin{abstract}
The Cultural Property Act was put into force in 1982 in Taiwan. Hundreds of buildings have been listed as either monuments or historic buildings since the law was enacted. Following the Cultural Property Act, many monuments and historic buildings have been restored and either continuously used in their original functions or adaptively reused for new functions. In recent years, creating a space to display the history of the particular buildings has become a must. The historical information represented and displayed in such exhibitions may include the history of the building, the designer (architect), the features of the building, and the restoration process, as well as historic relics and documents related to the building. This paper will discuss the design of such historical spaces and their roles as educational settings, with a focus on the Japanese-Period monuments and historic Buildings in Taiwan.
\end{abstract}

Index Terms-Representation, display of history, Japanese period, architectural heritage, Taiwan.

\section{INTRODUCTION}

Architecture can tell the story of nations, cultures, and history. It can also illustrate the story of regimes and societies, as well as families and individuals. Consequently, the preservation of monuments and historic buildings is very important at national, social, cultural, family, and individual level. In Taiwan, the Cultural Property Act was put into force in 1982; following this, hundreds of buildings have been listed as either monuments or historic buildings. Among them, many examples were constructed in the Japanese Period (1895 - 1945). Since most of these Japanese Period examples have been reused as new functions that differ from their original ones, many visitors are unable to understand the history of the buildings, since no historical information is provided. In recent years, it has become common to create a space in which to display this historical information. This paper will discuss the design of such historical spaces and their roles as either tourist attractions or educational settings.

\section{RESEARCH SAMPLES AND METHODOLOGY}

Four buildings with diverse functions will be chosen as study samples. The first is the former Taipei Prefecture Hall, which is now reused as "Control Yuan," one of the five branches of the Taiwanese Government and an investigatory agency that monitors the other branches of government. The second is the former Tainan Prefecture Hall, which is now

Manuscript received December 1, 2014; revised January 20, 2015.

Tsai-Chuan Chang is with the Department of Interior Design, Tainan University of Technology, Taiwan (e-mail: t60010@mail.tut.edu.tw). reused as the National Museum of Taiwan Literature and Cultural Heritage Research Center. The third is the former Bureau of Communication Building, which is now reused as Academia Historica. The fourth is the former Taipei Branch of Nippon Kangyo Bank, now Taiwan Land Bank Exhibition Hall of National Taiwan Museum. Inside each of these examples, either a particular space or a room is reserved for displaying information on the building's architectural history. The methods used in this study basically involve field investigations and the document-based research. The paper will discuss the history, features, and artifacts of the heritage properties and their display at a comparative level so as to build up academic references for these buildings.

\section{History AND FEATURES OF Heritage Properties}

Every building has its own story which is especially important when the building becomes a heritage property. All samples in this study have a unique history. Taiwan was ceded to Japan as her first colony in 1895 . The administration system of Colonial Taiwan was readjusted several times during the colonization period. In the beginning of the Japanese governance, the administration center of every prefecture was located in the former Qing Dynasty buildings. Beginning from the 1910s, the construction of new buildings for prefectural administration started. Taipei Prefecture Hall was completed in 1918, while Tainan Prefecture Hall was dedicated in 1916. After World War II, the former Taipei Prefecture Hall was reused as Control Yuan and it has maintained the same function to date. The former Tainan Prefecture Hall became the Headquarters of the Air Force Supply Commander (1949-1969) and Tainan City Hall (1969 - 1997). Now, it houses the National Museum of Taiwan Literature and Cultural Heritage Research Center. [4] The former Bureau of Communications Building was built in 1924. It became the Ministry of Communications, after WWII and reused as Academia Historica in recent years. The former Taipei Branch of Nippon Kangyo Bank was built in 1933. It is now reused as the Taiwan Land Bank Exhibition Hall of National Taiwan Museum [1].

As can be seen from the above, two of the research samples were designed in the 1910s and two after the 1920s. Their expressions are quite different. Both the former Taipei Prefecture Hall and the former Tainan Prefecture Hall were designed by Moriyama Matsunosuke, an architect from the construction department of the Office of the Governor-General. Besides their individual design characteristics, these two buildings have several similarities that reflect the attitudes of the colonial government. When Taiwan was colonialized by the Japanese, Western 
historical-style buildings were introduced to Taiwan as a symbol of modernity and power. Similarly, both the Taipei Prefecture Hall and the Tainan Prefecture Hall are located in the center of the city. In front of both buildings are circuses containing statues of the Governor-General [1].

The site plan of the Taipei Prefecture Hall is in the shape of an "L" while its Tainan counterpart is in the shape of a"V". A courtyard is located within both buildings. The main entrance of each building is centrally located with a porch supported by Tuscan-order columns. The Taipei Prefecture Hall is crowned with a flat dome while the Tainan case is topped by a Mansard roof and is flanked by twin towers. Inside the lobby of both buildings is a grand staircase leading to the upper floor. In the Taipei Prefecture Hall, the dome can be seen directly from the lobby since the floor above is void. The governmental buildings in the Japanese Colonial Period have a very specific typological design and construction. However, each building has its own characteristics in terms of details and expressions [1].

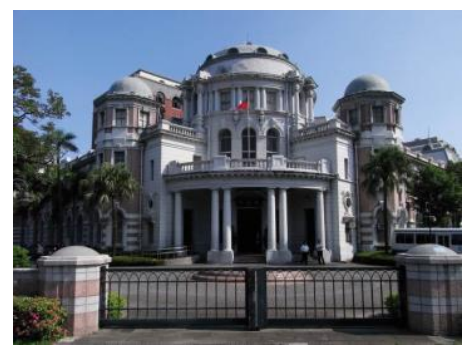

Fig. 1. Former Taipei prefecture hall, Taipei.

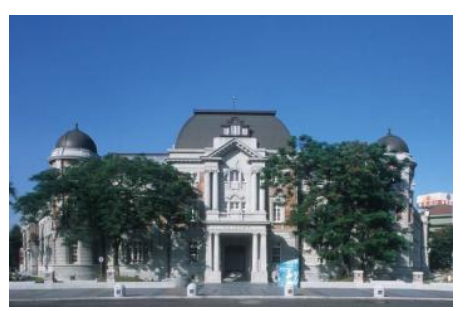

Fig. 2. Former Tainan prefecture hall, Tainan.

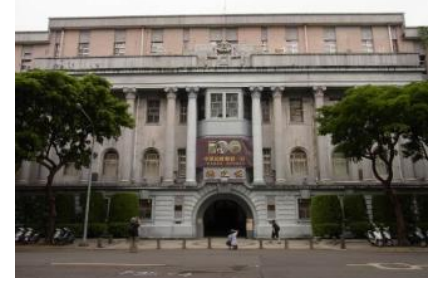

Fig. 3. Former bureau of communications building, Taipei.

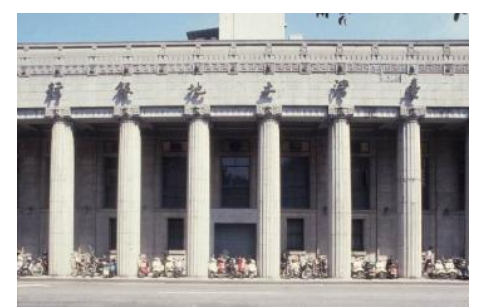

Fig. 4. Former Taipei branch of Nippon Kangyo bank, Taipei.

In contrast to the Taipei Prefecture Hall and the Tainan Prefecture Hall, which each has an accent on the corners of their facades; both the former Bureau of Communications
Building and the former Taipei Branch of Nippon Kangyo Bank stressed their facades facing the street. The corners of these two buildings were less noticed. In both cases, a colonnade dominates the facade. With respect to the built form, both buildings consist of a single mass. Inside the former Communications Building, there is a lobby with a grand staircase leading to the up floors. Inside the former Bank Building, a spacious commercial lobby dominates the ground floor, as was typical of banks in the 1930s [2].

The architectural history of the buildings can be displayed in two basic ways. In the first, the building itself is treated as the object that is on display. In the second, the contents are displayed in a specific room or dedicated space. Preserving the original building integrity authentically is central aim of either form of exhibition. Visitors can experience the full-scale architecture within the original site and city which entails interaction with the environment, time and seasons. This is the best way to understand the context of the original building and its meanings. Several issues such as the significance of the building, how the building can be preserved within the context, and how the building should be adapted for its new function, require careful consideration. In the former Taipei Prefecture Hall, which has been preserved and adaptively reused as "Control Yuan", the lobby and the monumental staircase are areas that visitors can still experience. The lobby is three-stories high, and the unique dome is directly above the lobby. The best way to experience these two elements and to see their beauty is to walk up and down the staircase and feel the change in scale and the interplay between light and space.

In the former Tainan Prefecture Hall, the front part of the building was preserved with an addition at the back to accommodate the new National Museum of Taiwan Literature and Cultural Heritage Research Center. A new Mansard roof was restored in 2003, to replace the roof that was incorrectly restored previously. The space in front of the building combines green areas and the circus, and can be used as a venue to host various events and festivals occurring either day or night. The new addition at the back of the former Tainan Prefecture Hall is now used as a cultural space. The beauty of the brick arcade within the original building has become the background and focus of any activity that occurs in the building. Natural light is admitted from the gap between the addition and the original structure, and this gives rises to changes in the light/shadow and texture within the building which has enriched the quality of the interior. In some cases, the arches have been used as part of exhibitions in the space; they have also been used to frame the exhibited objects. They could be considered as a defining element of the space. They can also be inserted by the glass so as to achieve a transparent and reflective effect, and thus represent the structure of the original building. The original cast-iron water pipes have the effect of dividing the facade of the building vertically. They are now used to hang display flags, and the verticality of the original elements has thus been preserved. The original window has been integrated into the exhibition space to form the study room of a writer. Original architectural elements become the scene of the exhibition. While the original building has been preserved; its unique elements have also been reinforced and mixed into new 
spaces.

In addition to treating architecture itself as an object for exhibition, all of the four heritage buildings have reserved a special room in which to display historic information and artifacts. The contents inside this display room include textual narratives, presentations, and analyses of the building's preservation and hidden parts as well as intangible historical information. The location of the display room is determined by designers, who must consider the circulation of visitors to the whole building. In all cases, the location of the display room can be easily accessed by visitors. In the former Taipei Prefecture Hall, this room is located on the second floor; in Tainan's case, the room is on the ground floor. The display room in the Tainan Prefecture Hall was developed in two stages, with changes in the location used. The first stage was to plan a special large exhibition room soon after the building's restoration was completed. After several years' display, "the special exhibition room" was re-designed to become a "permanent display room," and the size of the display area, as well as the number of exhibition objects were reduced. The display media were also changed to meet contemporary needs. However, the location of the display room during both stages remained beside the building's lobby.

In the Taipei Prefecture Hall, visitors have to experience the magnificent two-story-high lobby and climb up the grand staircase before entering the display room which is situated on the second floor. However, in the Tainan Prefecture Hall, visitors reach the display room immediately upon entering the building. Visitors are then meant to explore the building after visiting the display room. [3] In the former Communications Building, the display room is on the second floor; visitors can reach it either from the grand staircase or via the elevator. The display in the Bank Building is located on the third floor, in the northeastern. To access the room, visitors can use either a staircase nearby or a new elevator that has been added at the rear of the main building block.

\section{Historic ARTIFACTS AND TheIR DisPlay CONTENTS}

In the display room of a heritage property, the contents of the exhibition are basically grouped to six categories; namely, history, architect, building and site model, structure and in situ exhibition, architectural elements and building materials, and restoration concepts and methods.

\section{A. Architectural History}

Generally speaking, displays on the buildings' architectural history provide information to visitors regarding the date of the buildings' creation, the purpose and function of the buildings, and their current condition. In the Taipei Prefecture Hall, Communications Building, and Bank Building, the method used to display the architectural history is almost identical; that is, both architectural drawings and textual narratives regarding building's development are displayed on the printed panels. In the Tainan Prefecture Hall, architectural history is displayed via a "time-line". The use of fewer words and more photos make this exhibition easily to understand. Black blocks are used in the time-line to help the photos to stand out, and a side light of the light box on the time-line help to highlight the effect. Due to limitations related to space, the original display was replaced by an animation time-line display at the permanent exhibition of the Tainan Prefecture Hall. Instead of using the whole wall, the architectural history display is now presented using an animated time-line.

\section{B. Architect}

Coincidentally, the architect of Taipei Prefecture Hall, Tainan Prefecture Hall and Communications Building is the same person, Moriyama Matsunosuke, who is the most representative official architect during the Taiso Period of Japanese Colonization in Taiwan. He designed many important governmental buildings, including the Office of the Governor-General. Details on special architectural elements and the architect have been placed on the same display panel in the Taipei Prefecture Hall. In the Tainan Prefecture Hall, a display method similar to the one used to convey the architectural history for continuity. Other buildings designed by the same architect are also mentioned so that visitors can obtain a deeper understanding of his works. In all three cases, chronological presentation of the buildings designed by the architect is the main theme of the display, which was achieved by the contrast of light and short narrations [2].

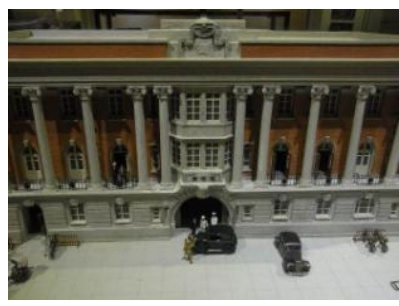

Fig. 5. Display model of the former bureau of communications building.

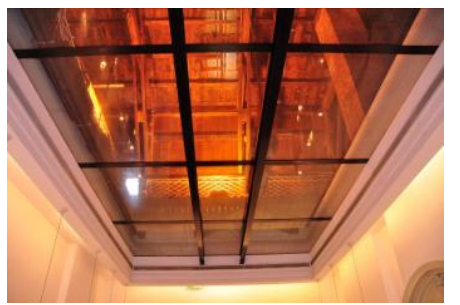

Fig. 6. Display of the roof truss in the former Taipei prefecture hall.

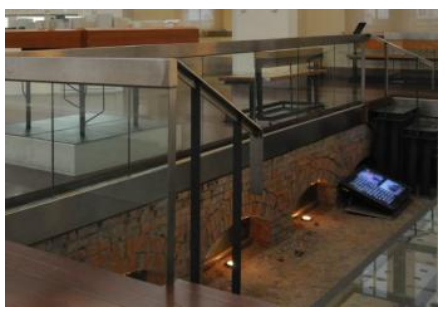

Fig. 7. In situ display of the raised foundation in the former Tainan prefecture hall.

\section{Building and Site Model}

Building and site models are the most direct way to outline the site plan and formal expression of the building for visitors. It is a necessity in any architectural exhibition. Because of the size of the model, it often occupies a prominent location within the exhibition. In the Taipei Prefecture Hall, the model 
is located at the end of the axis, forming the focus of the display room. In the Tainan Prefecture Hall, the model is located at the intersection of the two axes of the irregular room. [3] In the Communications Building and the Bank Building, the models are exhibited in the display room.

\section{Structure and in Situ Exhibition}

The structure of the buildings determines their overall shapes and silhouettes, and can be compared to bone under skin, which we seldom see. The location of the display room of the Taipei Prefecture Hall is on the second floor, which allows for the removal of a portion of the ceiling so that visitors could see the truss of the Mansard roof. Since the steep slope of a Mansard roof is extremely monumental if looks afar, it became a common feature during the Japanese period [3].

Raising buildings above the ground in order to limit damage from moisture and pests is a common construction feature in the West. The Japanese learned the knowledge and applied it to the governmental buildings in Taiwan. The increase in height can also help to increase the monumentality of a building. In the Tainan Prefecture Hall, four different parts of the raised foundation, which is one meter high, have been dug out, exposed, and exhibited in situ. In the first stage of the special exhibition, visitors are allowed to walk down to these excavated portions and see in a very close distance the arches of the foundation and their ventilation function.

The concrete paving on the bottom of the Hall's foundation also serves as a mechanism for moisture and pest prevention, and can also be seen in detail. During the second stage of the permanent exhibition, the excavated areas were covered with the heavy glass and illuminated with light, while the room is treated as a darker room suitable for light projection. These two display methods create different atmospheres in each stage, while retaining the idea that the brick arches and beams of the foundation must be seen. [3]

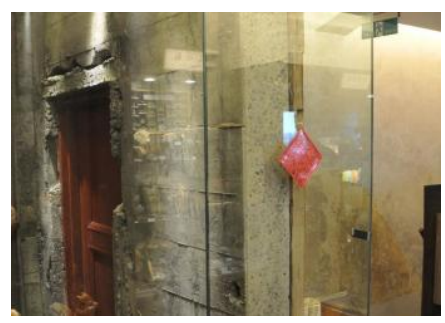

Fig. 8. Display of a section of structural wall in the former Taipei branch of Nippon Kangyo bank.

In the Communications Building, the finishing materials of some parts of the ceiling and walls have been removed so that visitors can see the authentic reinforced concrete structure beneath. However, in the Bank Building, the structural system is conveyed to visitors using copies of original drawings and samples taken from the structural wall.

\section{E. Architectural Elements and Building Materials}

The scale of the various architectural elements and building materials varies. They can be as large as a tower or as small as a brick. The location of the architectural elements is crucial to our understanding of them. Within the Taipei Prefecture Hall, enlarged drawings and photos are arranged around the building on display panels with lines connecting the displays to the corresponding locations. Details of the original roof tiles, metal components, and ceilings can be seen. The fireplace has been preserved in situ.

In the first stage of the special exhibition of the Tainan Prefecture Hall, architectural elements and building materials, including bricks, roof tiles, joints, and metal objects, were collected and displayed on a specially designed wall. They are indexed in a special facade photo to show where they are located in the building. A model of the roof truss is hanged above the display wall to indicate the location in the building. Furthermore, a sash window is mounted on the display wall to reveal the construction and parts of the installment. The window is so designed in such a way that visitors can experience the light weight of it for themselves when they lift it.

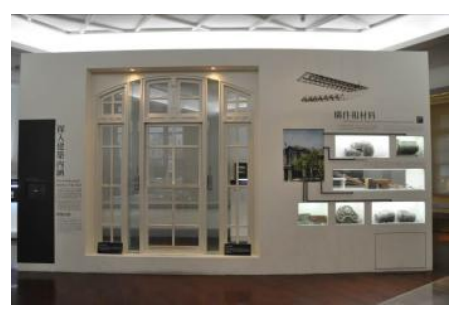

Fig. 9. Display wall of architectural elements in the former Tainan prefecture hall.

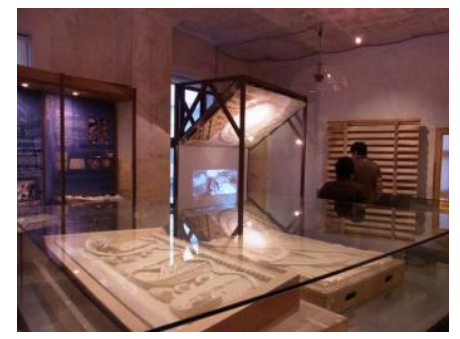

Fig. 10. Display of architectural elements in the former Taipei Branch of Nippon Kangyo bank.

To preserve the sash window in the very limited space in the second stage permanent exhibition, a concise explanation was inscribed directly on the glass of the window itself. Other small components and building materials are displayed on a transparent shelf that can be seen from the entrance lobby, and form an integrated part of the display scene. The large-scale elements are displayed with the help of visual interactive facilities. Visitors can use a special monitor to virtually select different parts of the building façade, and are then provided with the name and information of various elements chosen. In the other three examples, important architectural elements are collected. Some items are displayed in specially designed cupboards and exhibition shelves, while others are presented on walls or tables. The large safe room that was used to store money and gold is one of the attractions within the Banking Building.

\section{F. Adaptive Reuse}

All four building examples discussed in this paper have already been designated and preserved as cultural heritage by means of adaptive reuse. The significance of the reuse in each building is conveyed to visitors using displays that detail the range of processes and strategies used. In the Taipei Prefecture Hall, panels detailing the reuse process, especially a search for the original black tiles and their reproduction are the focus of the story. In the special exhibition of the former 
Tainan Prefecture Hall, multi-media images are used to display the motivation and process related to the building's restoration. The finishing of one wall has been removed to show some of the hidden elements of the restoration via an in situ display. The reinforced structure enables visitors to understand the importance of the structure. In the permanent exhibition, this part of the display is expanded to form a display shelf that contains visual and narrative descriptions, as well as films of interviews with scholars. These interviews explore the features of the building, as well as its historical meaning and the significance of the reuse. The display related to the building's reuse is thus highly educational [3], [4].

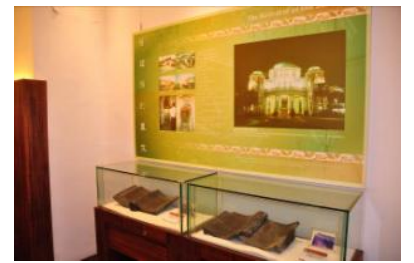

Fig. 11. The story of the black tiles is one focus of display in the former Taipei prefecture hall.

In the former Communications Building, some rooms have been reserved as the offices of Academia Historica. In addition, certain rooms are reserved for an exhibition related to the presidents and vice-presidents of Taiwan. However, a large room has been adaptively reused as the display room for the building. In this display room, panels, models, and several original elements preserved in the process of the restoration are displayed. The construction techniques can also be seen in a wall from which the finishing has been removed.

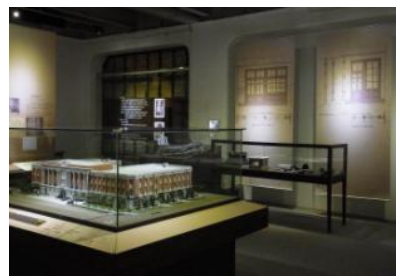

Fig. 12. Display room in the former communications department building of the bureau of transportation.

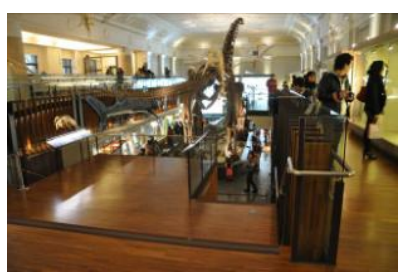

Fig. 13. Exhibition space in the former Taipei branch of Nippon Kangyo bank.

In the former Bank building, the original banking hall has been adaptively reused as an exhibition hall in which natural items are displayed, including a giant dinosaur skeleton, and animal and bird specimens. [5] In this hall, mezzanines and platforms have been added to create different spaces. The frieze in this room has also been restored in such a manner that the original and restored parts can be distinguished from one another.

\section{CONCLUSION}

The architectural history of the former Taipei Prefecture Hall and former Tainan Prefecture Hall is a history of Japanese Colonial Taiwan in miniature, indicating the scale of modernization in Taiwan during the period. The damage done to these buildings during WWII was also seen across the whole of Taiwan. The development of post-war Taiwan, with respect to its cultural heritage, witnessed an increasingly positive attitude towards the reuse of old buildings. The former Bureau of Communications Building became the Ministry of Communications after 1949, and was then reused as Academia Historica after the Ministry relocated. The former building of the Kangyo Bank's Taipei Branch, is an important cultural heritage site that has witnessed the country's financial development. It became the headquarters of the Land Bank of Taiwan after 1945. The building is an architectural treasure, with a unique style rarely seen in Taiwan. Although the bank was faced with the threat of demolition in the 1990s, it was saved thanks to its cultural and architectural significance, and finally became a division of the National Taiwan Museum. The restoration of both the former Communications Building and the former Bank Building, reveals the advanced technology used in restoration as well as new concepts of conservation.

This research concludes that adaptive reuse does not involve merely passively preserving a structure or a shelter, but to use it in a positive way. Successfully reused buildings can be enhanced via the establishment of a display room or space that presents the building's values as cultural heritage. The display rooms in all examples here tell the stories of the building themselves, as well as that of a specific period in Taiwan. It is hoped that more attention will be paid to the reuse of the hundreds of buildings listed as cultural heritage according to the Cultural Property Act of Taiwan, and how their stories are told, because those stories will become the best mechanism for the historic and cultural education of Taiwan.

\section{REFERENCES}

[1] C. C. Fu, A History of Modern Architecture in Taiwan, Taipei: The Architectural Institute of Taiwan, 2013.

[2] C. C. Fu, Architectural Heritage of Taiwan - The Japanese Period, Tainan: Taiwan Architecture and Cultural Property Press, 2009.

[3] T. C. Chang, "Telling their own stories - representing historical information in monuments and historic buildings in Taiwan" in Proc. the Fourth Asian Conference on Arts and Humanities, Osaka, 2013, pp. 710-725.

[4] S. C. Fan and M. L. Chiou, Old Building, New Life, Tainan: National Research Center of Cultural Heritage, 2003.

[5] T. N. Li, The Story of Collection in A Century, Taipei: National Taiwan Museum, 2009.

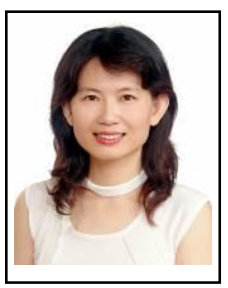

Tsai-Chuan Chang received her B. Arch degree from Chung Yuan Christian University in Taiwan and M.F.A. degree from the School of the Art Institute of Chicago. She has taught at the Tainan University of Technology in Taiwan since 1992 where she is an assistant professor. Her major research interests are architectural history and the adaptive reuse of historical buildings. 